\title{
REDUCING CONCRETE PERMEABILITY BY USING NATURAL POZZOLANS AND REDUCED AGGREGATE-TO-PASTERATIO
}

\author{
Fernando BUSTOS ${ }^{a}$, Patricia MARTINEZ ${ }^{\mathrm{b}}$, Carlos VIDELA ${ }^{\mathrm{a}}$, Mauricio LOPEZ ${ }^{\mathrm{a}}$ \\ ${ }^{a}$ Department of Construction Engineering and Management, School of Engineering, \\ Pontificia Universidad Catolica de Chile, Santiago, Chile \\ ${ }^{b}$ School of Engineering, Universidad de Valparaiso, Valparaiso, Chile
}

Received 25 Mar 2012; accepted 16 Aug 2012

\begin{abstract}
Improved durability of concrete is mainly achieved with low-permeability. Permeability depends on permeability of the bulk cement paste (CP) and that of its interfacial transition zone (ITZ). Even though permeability of CP is well understood and can be adequately controlled, permeability of ITZ is not well understood yet. This paper shows that minimizing permeability of concrete requires minimizing permeability of $\mathrm{CP}$ by using a supplementary cementing material (SCM) such as natural pozzolans (NP) and minimizing ITZ by reducing aggregate content until maximum cement content. This was done by comparing performance of concrete made with ordinary Portland cement (OPC) and blended cement $(\mathrm{OPC}+\mathrm{NP})$ at the same $\mathrm{w} / \mathrm{b}$, and by comparing performance of concrete with different amount of ITZ at the same w/b. All of this was performed through testing of mechanical properties, air permeability, sorptivity, chloride ion diffusion, and aggregate specific surface. Results show that NP reduced air permeability by $84 \%$ and chloride ion diffusion by $66 \%$, but increased sorptivity up to $140 \%$. ITZ has an important effect in all properties; especially in air permeability where sensitive reduction of more than a $90 \%$ was achieved. ITZ effect seems to be as important as using SCMs in improving durability of concrete.
\end{abstract}

Keywords: durability, natural pozzolans, transport mechanisms, air-permeability, sorptivity, chlorides.

\section{Introduction}

\section{Relevance of durability}

Sustainability one of the most important challenges that construction industry faces nowadays, and it is still not clear how to specify structures for sustainability. Overspecification is both wasteful and unfair to the client while under-specification leads to premature and costly repair work (Richardson 2004), and neither of these practices are sustainable. Further, deterioration of materials makes structures unsafe which also poses a sustainability concern. Durability of materials, specifically that of reinforced concrete, has gained a main role in advancing sustainable construction by increasing safety and reducing maintenance and rehabilitation of structures (Shen et al. 2007). Nevertheless, specifications for durable concrete are still a challenge.

Compressive strength is the main, and most of the time the only, property used to specify hardened concrete. Therefore, traditionally mixture designs focus on achieving the specified strength without considering other concrete properties affecting durability (Mindness 2005) and these can be as important as compressive strength.
Although compressive strength and durability depend on similar factors, achieving one of them does not guarantee achieving the other, so special care needs to be taken to achieve both (Hooton 2006). Since there is no a recipe to ensure durability (Neville 2001), there is the need to investigate different ways to improve concrete durability without affecting compressive strength.

Even when some designers are more aware of the importance of evaluating durability of structures to ensure the mechanical properties during service life and to estimate the actual cost of the structure (Mehta, Monteiro 2006), contractors usually do not have a thorough knowledge about how to ensure durability. The problem becomes more complex because the information from durability tests is fragmented and cannot be easily synthesized to understand durability from a broad point of view (Mehta 1991).

Four deleterious agents have been identified as critical to concrete durability because their potential to produce corrosion in reinforced concrete. They are: water, chlorides, carbon dioxide, and oxygen. Thus, the ease with which these agents enter into and move through concrete, referred to as permeability (Neville 2004), needs to be measured to assess concrete durability.

Corresponding author: Mauricio Lopez

E-mail:mlopez@ing.puc.cl 
It is well accepted that permeability is a good indicator of durability potential (Bentz 2002).

Permeability of concrete is adequately explained by the transport processes in concrete which are mainly four: (1) transport of water under a hydrostatic pressure head; (2) transport of water by capillary suction; (3) diffusion of ions under a concentration gradient; and (4) transport of ions by moving fluid (Alexander 2005; Garboczi 1995).

Concrete permeability testing cannot be replaced by using the many probabilistic models developed to explain concrete deterioration, as proposed by Ferreira (2010) and by Kliukas and Kudzys (2004), despite their recent considerable improvements.

\section{Supplementary cementing materials (SCMs) in durability of concrete}

The addition of SCMs is an effective way to decrease permeability of concrete (CEB 1997; Mehta, Monteiro 2006; Neville 2004). Silica fume and fly ash are among the most widely used SCMs, but natural pozzolans have proven to greatly impact concrete performance (CEB 1997).

Pozzolans are natural or artificial materials containing silica in a reactive form (Neville 2004). Pozzolans react with the calcium hydroxide, derived from cement hydration, and water forming new calcium silicate hydrates $(\mathrm{C}-\mathrm{S}-\mathrm{H})$ that increase compressive strength and reduce permeability.

The use of SCMs have proven to improve durability of concrete and provide additional benefits such as improvement in workability, reduction of the heat of hydration, reduction in permeability, increase in ultimate strength, increase in resistance to sulphate attack, and reduction in alkali-silica reaction (Rodríguez-Camacho, Uribe-Afif 2002; Uzal, Turanli 2003; Papadakis, Tsimas 2002).

Among many types of SCMs, natural pozzolans have gained more attention lately because they might be widely available, such as some clays and volcanic ashes. These materials do not depend on other industries, unlike SCMs such as silica fume, fly ash and ground granulated blast furnace slag.

As with other SCMs, the use of natural pozzolans modifies concrete microstructure, improving concrete properties such as strength and permeability (Colak 2002; Sabir et al. 2001). Even more, the improvement in permeability appears to be very significant when compared to that in strength (Lopez, Castro 2010).

\section{Factors affecting permeability}

Permeability of concrete depends on the permeability of the cement paste, aggregate, and interfacial transition zone (ITZ). However, according to many (for example, (Richardson 2004), permeability of concrete is predominantly controlled by the permeability of cement paste and that of ITZ. For porous and permeable aggregates, hydration products can penetrate superficial pores "sealing" the aggregate and restricting the overall permeability to that of the cement paste or ITZ. For non-porous aggregates the tortuosity of the pore structure increases drastically, decreasing intrinsic permeability to values lower than that of cement paste or ITZ (Carcasses, Ollivier 1999).

Water-to-binder ratio by weight $(\mathrm{w} / \mathrm{b})$ appears to be the main factor controlling permeability of cement paste (CEB 1997; Neville 2004), since it determines the initial space between unhydrated cement and the porosity and ultimately depercolation of pore structure (Powers et al. 1959; Powers 1960).

Mixing water is indirectly responsible for the permeability of hydrated cement paste (Mehta, Monteiro 2006), since it determines total and unfilled space in the cement paste microstructure after water has been consumed either by cement hydration or by evaporation. Thus, lower mixing water contents will decrease permeability of cement paste. On the other hand, very high cement contents do not necessarily decrease permeability; there seems to be an optimum cement content for decreasing permeability (Zhang, Gjorv 1991), since increasing cement content makes concrete more prone to heating and thermal cracking.

Microcracks, normally present in the ITZ, increase permeability of concrete above that of the corresponding cement paste. From this perspective, ITZ effects on permeability become more important as aggregate volume increases (Carcasses, Ollivier 1999).

The relevance of the ITZ on permeability of concrete is not only explained by microcracks, but also by differences in microstructure with the bulk cement paste. For instance, it has been established that the thin water film formed around large aggregate particles increases w/b locally producing a weaker and more permeable zone with respect to bulk cement paste (Mehta, Monteiro 2006). For instance, Bourdette et al. (1995) measured very high porosity at the ITZ concluding that it plays an important role in the ion diffusion process. Additionally, another study focused on cement paste and mortars (Tumidajski 1996), observed that the conductivity of the system decreases more or less linearly with an increase in the volume fraction of the aggregates. Accounting the dilution effect of aggregates, Tumidajski concluded that the ITZ had very little effect on the electrical conductivity of the overall system for an aggregate-to-mortar ratio over 0.1. Oppositely, Ping et al. (1991a) used the same technique to obtain results suggesting that the ITZ had an important effect on both the electrical conductivity and permeability.

Another study (Mills 1987) concluded that for a given strength and workability (i.e. constant $w / b$ ), permeability decreases as cement content decreases because the initial amount of mixing water determines the total porosity of the system. Such results may be explained based on the low w/b and superplasticizer that make ITZ microstructure very similar to that of the bulk paste (Carcasses, Ollivier 1999). 
One possible explanation to the opposing conclusions above is that the effect of the aggregate on concrete transport properties cannot be solely evaluated by simply accounting for the dilution effect; according to Carcasses and Ollivier (1999), from the model developed by Garboczi (1995), dilution, tortuosity and the intrinsic influence of porous ITZ appears to be all important in determining permeability of concrete. This is consistent with the conclusions obtained previously (Bourdette et al. 1995); that is, tortuosity of ITZ tends to have greater influence on the transport properties than the connectivity of the ITZ.

Igusa (Carcasses, Ollivier 1999), using a threephase model demonstrated that permeability of ITZ is higher than that of bulk cement paste by estimating the following properties for ITZ: thickness of 20 microns, conductivity being 6 times greater than that of cement paste, and porosity being 1.7 times greater than that of cement paste.

Ping et al. (1991b), using quartz and limestone aggregate, determined that the thickness of ITZ decreases when reducing the maximum size of the aggregate. The ITZ using both types of aggregate was less dense than that of the bulk paste, but when using limestone, there was a critical particle size value below which ITZ becomes denser than the bulk paste. This was significant for aggregate sizes below $0.19 \mathrm{~mm}$.

Overall, it can be stated that the use of natural pozzolans can be beneficial in decreasing permeability of cement paste and concrete, but controlling the permeability and amount of ITZ could be even more beneficial. Thus, assessing the amount of ITZ is necessary to estimate or understand its effect on permeability of concrete and to obtain a mixture design for low permeability.

\section{Research significance}

SCM are widely used as a cement replacement nowadays and their influence on durability has been extensively studied. However, there are few studies using natural pozzolans, despite their widespread use as an SCM in many countries. This paper assesses the effect of natural pozzolans on durability of concrete by measuring air permeability, sorptivity and chloride ion diffusion; In addition, it assesses the effects of ITZ on the transport properties of concrete by using different aggregate-to-paste ratios, at the same $\mathrm{w} / \mathrm{b}$. Stereology was used to determine the specific surface of aggregate, and estimate the potential amount of ITZ, to ultimately describe the effect of ITZ in permeability of concrete. It was of interest to determine the relative importance of the effect of natural pozzolans and ITZ.

\section{Experimental method}

The experimental program considered the fabrication of four mixtures for assessing the influence of natural pozzolans and ITZ on the permeability of concrete. Permeability was evaluated by measuring transport properties with specific methods: sorptivity controlled by water capillary suction, air permeability, and chloride penetration test controlled by chloride ion diffusion. This approach aimed to assess transport properties of concrete in both: 1) in an unsaturated pore system where sorptivity and gas diffusion may dominate; and 2) in a saturated pore system, at normal pressure, where chloride ion diffusion is the predominant transport mechanism (Zhang, Gjorv 1991). ITZ, on the other hand, was assessed based on the surface density of the aggregate by using stereology and microscopy.

\subsection{Materials and mixtures}

OPC and blended cement (OPC with natural pozzolans) were used in the trial mixtures. The coarse aggregate had a saturated surface dry (SSD) density of $2585 \mathrm{~kg} / \mathrm{m}^{3}$ and absorption of $1.4 \%$, and the fine aggregate has a SSD density of $2810 \mathrm{~kg} / \mathrm{m}^{3}$ and absorption of $1.1 \%$.

The effect of natural pozzolans in transport properties was assessed by comparing the performance of two concrete mixtures; $\mathrm{C} 1$ and $\mathrm{C} 2$. Both had the same mixture proportions, w/b of 0.5 , with the only difference being the cement type: $\mathrm{C} 1$ used $\mathrm{OPC}$ and $\mathrm{C} 2$ used blended cement consisting of $62 \%$ OPC and $38 \%$ natural pozzolans. The effect of ITZ in transport properties was assessed by comparing the performance of three mixtures: $\mathrm{C} 2$, $\mathrm{C} 3$, and $\mathrm{C} 4$. All of them with the same blended cement, $\mathrm{w} / \mathrm{b}$ of 0.5 , with the only difference being the aggregateto-paste ratios by volume (a/cp): $\mathrm{C} 2 \mathrm{had}$ a a/cp of 2.57 (335 kg/m 3 of cement), C3 had a a/cp of $3.35\left(270 \mathrm{~kg} / \mathrm{m}^{3}\right.$ of cement), and C4 had a a/cp of $1.94\left(400 \mathrm{~kg} / \mathrm{m}^{3}\right.$ of cement). Mixture designs are summarized in Table 1.

\subsection{Test methods}

Compressive strength, splitting tensile strength, modulus of elasticity, sorptivity, air permeability and chloride ion diffusion were measured at different ages. The surface

Table 1. Concretes mixture design (amounts in $\mathrm{kg}$ per cubic meter of concrete)

\begin{tabular}{lcccc}
\hline Concrete & $\mathrm{C} 1$ & $\mathrm{C} 2$ & $\mathrm{C} 3$ & $\mathrm{C} 4$ \\
\hline Material & $\begin{array}{c}\text { Weight } \\
(\mathrm{kg})\end{array}$ & $\begin{array}{c}\text { Weight } \\
(\mathrm{kg})\end{array}$ & $\begin{array}{c}\text { Weight } \\
(\mathrm{kg})\end{array}$ & $\begin{array}{c}\text { Weight } \\
(\mathrm{kg})\end{array}$ \\
\hline Cement & 335 & 335 & 270 & 400 \\
\hline Water & 167.5 & 167.5 & 135 & 200 \\
\hline $\begin{array}{l}\text { Coarse } \\
\text { Aggregate }\end{array}$ & 1130 & 1109 & 1202 & 1024 \\
\hline Fine Aggregate & 753 & 739 & 801 & 682 \\
\hline Superplasticizer & 2.3 & 3.0 & 0.4 & 0.5 \\
\hline $\begin{array}{l}\text { w/b } \\
\begin{array}{l}\text { Aggregate } \\
\text { content by } \\
\text { volume (\%) }\end{array}\end{array}$ & 0.5 & 0.5 & 0.5 & 0.5 \\
\hline $\begin{array}{l}\text { Paste content by } \\
\text { volume (\%) }\end{array}$ & 29 & 31 & 25 & 36 \\
\hline
\end{tabular}


density of the aggregate for all mixtures was measured from an unbiased stereology technique.

Compressive strength was measured on $100 \times 200-\mathrm{mm}$ cylinders according to ASTM C39 / C39M - 10 at the age of 4, 7, 28, 90 and 150 days. Splitting tensile strength was also measured on $100 \times 200-\mathrm{mm}$ cylinder according to ASTM C496 / C496M - 04e1 at the age of 28, 90 and 150 days. Modulus of elasticity was measured on $150 \times 300 \mathrm{~mm}$ cylinders according to ASTM C469 / C469M - 10 at the age of 28,90 and 150 days.

Sorpitivity was measured on $100 \times 50$-mm cylinders according to ASTM C1585-04 at age of 28 and 90 days. The test consists of measuring the change in mass with time of a concrete specimen, previously dried at $50 \pm 2{ }^{\circ} \mathrm{C}$ and $80 \%$ relative humidity. One flat side of the specimen is exposed to water which produces a change of mass by capillary suction. Water loss is prevented by sealing the other sides and of the specimens by a plastic bag to avoid water evaporation. Figure 1 shows a schematic of the test.

Data collected during the first 6 hours of the test correspond to the "initial absorption" while that collected between 1 to 7 days correspond to the "secondary absorption". Results are plotted as the cumulative change in mass divided by exposed area and density of water ( $\mathrm{Y}$ axis), versus the square root of time ( $\mathrm{X}$ axis). The slopes of the initial and secondary absorption are calculated. Because each stage represents different mechanisms (i.e. capillary suction for the initial and diffusion for the secondary), a single coefficient is calculated from the intersection of the two slopes. According Castro et al. (2011), sorptivity results were normalized by paste content and by aggregate absorption because the important effect they have in the test.

It is important to note that sorptivity can be considered as an index for estimating potential durability of concrete (Hazaree et al. 2010; Pereira de Oliveira et al. 2006).

Air permeability was measured on 200 -mm cubes according to SN EN 206-1, 2003 (Swiss-Standard 2003) at age of 28,90 , and 150 days. Six measurements (one on each face) were taken on each specimen.

The test method consists of estimating air permeability by applying vacuum and measuring the air influx from within concrete. The perpendicular flow of air through concrete at the level of the surface is ensured by a guard ring that prevents air from the exterior affecting the measurement. Saturated or partially saturated pores will affect the air permeability, so the results need to be

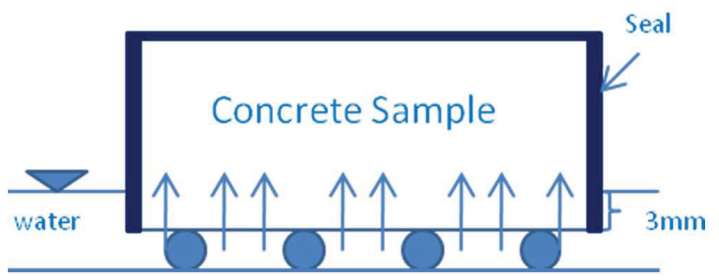

Fig. 1. Schematic of sorptivity test corrected by moisture (Torrent, Ebensperger 2010). In order to measure air permeability in a unsaturated pore system, specimens were removed from the fog room and kept at $50 \% \mathrm{RH}$ and $23{ }^{\circ} \mathrm{C}$ to air dry the superficial pores two days before testing. Figure 2 shows a schematic of the test. Since specimens were preconditioned, it is expected that internal relative humidity is similar for all mixtures; and therefore, results are comparable. However, this does not necessarily assure that water within the pore network is the same.

It is important to note that air permeability has become the preferred method for specifying and measuring durability of concrete in Switzerland (Swiss-Standard 2003).

Chloride ion diffusion was measured on $100 \times 50-\mathrm{mm}$ cylinders according to ASTM C1202-05 at the age of 35 and 97 days. In this method, an electrical potential of $60 \mathrm{~V}$ is maintained across the flat ends of saw-cut cylinders (previously conditioned), for 6 hours. One end is immersed in a $\mathrm{NaCl}$ solution and the other in a $\mathrm{NaOH}$ solution. Chloride ions travel across the specimens and the current is measured periodically. At the end of the 6 hours, the total charge passed, in coulombs, is calculated, and the concrete's ability to resist chloride ion penetration is obtained. Figure 3 shows a schematic of the test.

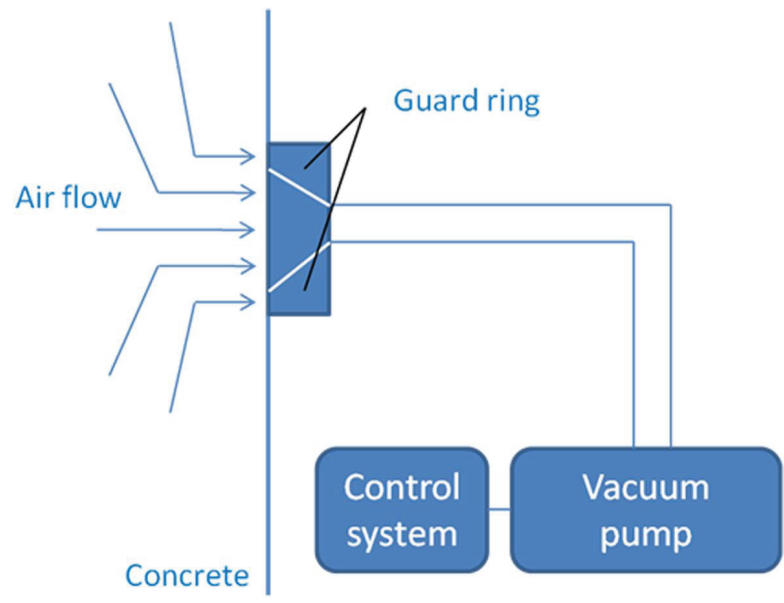

Fig. 2. Schematic of air permeability test

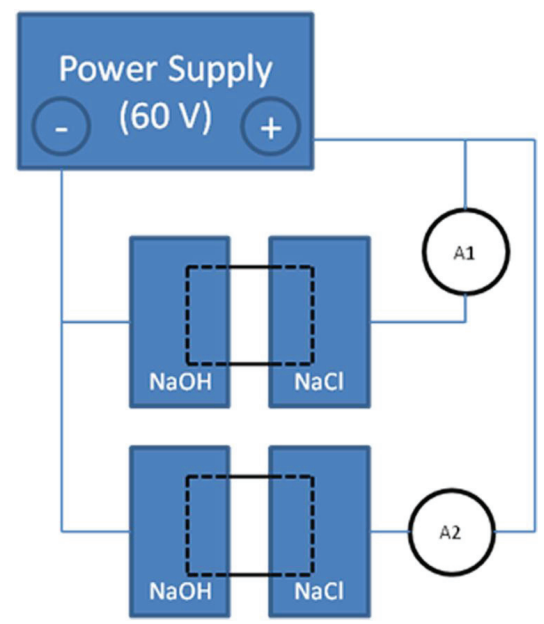

Fig. 3. Schematic of chloride ion diffusion test 
ITZ was assessed through measuring aggregate surface by means of stereology parameters, specifically "surface density". The estimation of surface density was made from vertical uniform random (VUR) sections using an unbiased stereology technique based on cycloids. Cycloids were used because they are considered isotropic lines on vertical uniform random sections in $3 \mathrm{D}$ space (Howard, Reed 2005).

Surface density is then estimated from:

$$
s_{v}(\text { Y.ref })=\frac{2 \times \sum_{i=1}^{n} I_{i}}{\frac{1}{p} \times \sum_{i=1}^{n} P_{i}},
$$

where: $I_{i}$ is the number of intersections; $P_{i}$ the points hitting the reference space; and $l / p$ is the length of test line per grid point at the level of the tissue, corrected for linear magnification (Howard, Reed 2005; Zhang, Han 2005).

Surface density of the aggregate was also estimated based on their particle size distribution (sieve analysis) and assuming spherical particles.

\section{Results and discussion}

\subsection{Cementitious materials}

Oxides analysis, specific weight and Blaine fineness was made for both, OPC and blended cement. The results are summarized in Table 2.

Blended cement had a considerably higher $\mathrm{SiO}_{2}$ content and lower specific gravity than OPC because of the inclusion of natural pozzolans. Content of $\mathrm{CaO}$, $\mathrm{Fe}_{2} \mathrm{O}_{3}$, and $\mathrm{Al}_{2} \mathrm{O}_{3}$, are all lower in blended cement than in OPC. The relatively high insoluble residue in the blended cement represents the natural pozzolans. Blaine fineness is similar in both cements.

Natural pozzolans present in the cement used for $\mathrm{C} 2, \mathrm{C} 3$ and $\mathrm{C} 4$, had a volcanic origin and could be classified as a Type-N pozzolan according to ASTM C618 (2008). It corresponded to a volcanic glass known as rhyolite pumicite. The chemical compositions of NP and OPC used in this investigation are shown in Table 3.

Table 2. Cements characterization

\begin{tabular}{lcc}
\hline & $\begin{array}{c}\text { Ordinary } \\
\text { Portland } \\
\text { cement }\end{array}$ & $\begin{array}{c}\text { Blended cement } \\
(62 \% \text { OPC }+38 \% \\
\text { natural pozzolans })\end{array}$ \\
\hline $\mathrm{SiO}_{2}(\%)$ & 19.4 & 33.6 \\
\hline $\mathrm{CaO}(\%)$ & 63.3 & 39.1 \\
\hline $\mathrm{Fe}_{2} \mathrm{O}_{3}(\%)$ & 2.9 & 1.6 \\
\hline $\mathrm{Al}_{2} \mathrm{O}_{3}(\%)$ & 6.4 & 4.0 \\
\hline $\mathrm{SO}_{3}(\%)$ & 2.7 & 2.62 \\
\hline $\mathrm{MgO}(\%)$ & 0.8 & 1.1 \\
\hline Loss on Ignition $(\%)$ & 1.4 & 3.4 \\
\hline Insoluble Residue $(\%)$ & 0.8 & 33.5 \\
\hline Specific gravity & 3.15 & 2.82 \\
\hline Specific surface $\left(\mathrm{cm}^{2} / \mathrm{gr}\right)$ & 4697 & 4876 \\
\hline
\end{tabular}

Table 3. Chemical composition of natural pozzolans (Espinoza et al. 2010)

\begin{tabular}{cccccc}
\hline $\begin{array}{c}\mathrm{SiO}_{2} \\
(\%)\end{array}$ & $\begin{array}{c}\mathrm{Al}_{2} \mathrm{O}_{3} \\
(\%)\end{array}$ & $\begin{array}{c}\mathrm{Fe}_{2} \mathrm{O}_{3} \\
(\%)\end{array}$ & $\begin{array}{c}\mathrm{CaO} \\
(\%)\end{array}$ & $\begin{array}{c}\mathrm{MgO} \\
(\%)\end{array}$ & $\begin{array}{c}\mathrm{K}_{2} \mathrm{O} \\
(\%)\end{array}$ \\
\hline 69.2 & 13.2 & 1.7 & 2.7 & 0.8 & 3.0 \\
\hline $\mathrm{SO}_{3}(\%)$ & $\begin{array}{c}\mathrm{Na}_{2} \mathrm{O} \\
(\%)\end{array}$ & $\begin{array}{c}\mathrm{TiO}_{2} \\
(\%)\end{array}$ & $\begin{array}{c}\mathrm{P}_{2} \mathrm{O}_{5} \\
(\%)\end{array}$ & LOI (\%) & \\
\hline 0.1 & 3.9 & 0.2 & 0.1 & 4.36 & \\
\hline
\end{tabular}

The chemical composition of the natural pozzolans used in this investigation suggests an almost negligible hydraulic activity ( $2.7 \%$ of $\mathrm{CaO}$ content), and a relatively high pozzolanic activity due to its $69.2 \%$ of $\mathrm{SiO}_{2}$.

\subsection{Concrete mixtures}

Average results for compressive strength, splitting tensile strength and modulus of elasticity at different ages are shown in Table 4, and average sorptivity coefficient, air permeability and chloride ion diffusion, are shown in Table 5.

\subsection{Effect of natural pozzolans}

The effect of the natural pozzolans in mechanical properties and permeability is analysed by comparing the performance of $\mathrm{C} 1$ with $\mathrm{OPC}$ and $\mathrm{C} 2$ with blended cement

Table 4. Mechanical properties of mixtures under investigation

\begin{tabular}{|c|c|c|c|c|}
\hline 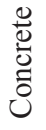 & $\begin{array}{l}\text { Age } \\
\text { (days) }\end{array}$ & $\begin{array}{c}\text { Compressive } \\
\text { strength } \\
(\mathrm{MPa})\end{array}$ & $\begin{array}{l}\text { Split test } \\
(\mathrm{MPa})\end{array}$ & $\begin{array}{l}\text { Elastic } \\
\text { modulus } \\
(\mathrm{MPa})\end{array}$ \\
\hline \multirow{5}{*}{$\bar{U}$} & 4 & 25.59 & - & - \\
\hline & 7 & 32.05 & - & - \\
\hline & 28 & 34.17 & 3.82 & 24.83 \\
\hline & 90 & 39.47 & 3.32 & 29.58 \\
\hline & 150 & 45.04 & 3.8 & 28.44 \\
\hline \multirow{5}{*}{ U } & 4 & 17.50 & - & - \\
\hline & 7 & 20.74 & - & - \\
\hline & 28 & 26.25 & 3.03 & 23.53 \\
\hline & 90 & 31.15 & 2.94 & 27.78 \\
\hline & 150 & 35.01 & 3.24 & 26.79 \\
\hline \multirow{5}{*}{$\tilde{U}$} & 4 & 12.24 & - & - \\
\hline & 7 & 14.73 & - & - \\
\hline & 28 & 21.66 & 1.35 & 23.89 \\
\hline & 90 & 25.35 & 2.38 & 25.68 \\
\hline & 150 & 27.23 & 3.88 & 26.36 \\
\hline \multirow{5}{*}{ オ } & 4 & 19.52 & - & - \\
\hline & 7 & 22.68 & - & - \\
\hline & 28 & 29.86 & 2.45 & 26.67 \\
\hline & 90 & 37.69 & 3.61 & 29.11 \\
\hline & 150 & 45.53 & 4.54 & 27.92 \\
\hline
\end{tabular}


Table 5. Durability properties of mixtures under investigation

\begin{tabular}{lccccccc}
\hline & $\begin{array}{c}\text { Sorptivity } \\
\text { coefficient }\end{array}$ & \multicolumn{2}{c}{ Air permeability } & \multicolumn{2}{c}{$\begin{array}{c}\text { Chloride ion } \\
\text { diffusion }\end{array}$} \\
\cline { 2 - 8 } & \multicolumn{2}{c}{$\mathrm{mm} / \mathrm{s}^{0.5}$} & \multicolumn{3}{c}{$10^{-6} \mathrm{~m}^{2}$} & \multicolumn{2}{c}{ Coulombs } \\
\hline days & 28 & 90 & 28 & 90 & 150 & 28 & 90 \\
\hline $\mathrm{C} 1$ & 0.60 & 0.21 & 1.10 & 0.40 & 0.11 & 4315 & 4437 \\
\hline $\mathrm{C} 2$ & 0.89 & 0.51 & 0.14 & 0.07 & 0.05 & 1522 & 1705 \\
\hline $\mathrm{C} 3$ & 1.34 & 0.69 & 0.98 & 1.22 & 0.50 & 2990 & 1432 \\
\hline $\mathrm{C} 4$ & 0.52 & 0.17 & 0.09 & 0.04 & 0.03 & 2327 & 781 \\
\hline
\end{tabular}

using the three proposed methods for characterizing transport properties.

\subsubsection{Compressive strength}

Figure 4 shows the compressive strength obtained for each of the mixtures under study.

When comparing $\mathrm{C} 1$ with $\mathrm{OPC}$ and $\mathrm{C} 2$ with blended cement with natural pozzolans, it can be concluded that the use of OPC provides higher compressive strength than the blended cement under investigation for all ages considered in this investigation. The maximum difference of $11.3 \mathrm{MPa}$ was obtained at 7 days of age representing $55 \%$ of the strength of $\mathrm{C} 2$. At 150 days of age, the difference was $10 \mathrm{MPa}$ and represented $28 \%$ of the strength of $\mathrm{C} 2$. That is, the relative difference between $\mathrm{C} 1$ and $\mathrm{C} 2$ decreased over time suggesting that the pozzolanic reaction of the natural pozzolans contributed to increased strength of $\mathrm{C} 2$ over time. Mixtures $\mathrm{C} 3$ and $\mathrm{C} 4$ also presented lower compressive strength than $\mathrm{C} 1$ at almost all ages with the main difference being that the difference in compressive strength between $\mathrm{C} 1$ and $\mathrm{C} 3$ increased with time and between $\mathrm{C} 1$ and $\mathrm{C} 4$ decreased with time; in fact 150-day compressive strength of $\mathrm{C} 1$ and $\mathrm{C} 4$ were almost the same.

The differences in splitting tensile strength between mixtures with OPC $(\mathrm{C} 1)$ and bended cement $(\mathrm{C} 2, \mathrm{C} 3$, and $\mathrm{C} 4$ ) are in most cases below 1.0 MPa and all decreases between 28 and 150 days of age.

Modulus of elasticity showed small differences between mixtures with OPC $(\mathrm{C} 1)$ and bended cement $(\mathrm{C} 2$, $\mathrm{C} 3$, and $\mathrm{C} 4$ ) being most below $2.0 \mathrm{GPa}(7 \%)$.

\subsubsection{Sorptivity coefficient}

Figure 5 presents the results for sorptivity coefficient normalized by the respective volume of paste content and aggregate absorption according to Castro et al. (2011) at 28 and 90 days of age. Results suggest that concrete containing natural pozzolans $(\mathrm{C} 2)$ present a higher sorptivity coefficient than concrete with OPC. Even though it has been demonstrated that the pozzolanic reaction of natural pozzolans produce more calcium silicate hydrates and create a more refined pore structure, this is not reflected in capillary suction of water at 90 days of age as shown previously (Lopez, Castro 2010).

Both concrete mixtures showed a decrease in sorptivity between 28 and 90 days of age; however, $\mathrm{C} 1$ with
OPC decreased more importantly relatively to $\mathrm{C} 2$ with natural pozzolans making the difference between them more important with age. Additionally, variability in sorptivity coefficient of $\mathrm{C} 1$ with OPC was lower than that of $\mathrm{C} 2$ with natural pozzolans.

\subsubsection{Air permeability}

The results for air permeability in logarithmic scale versus the age at testing are shown in Figure 6, and Table 6 presents the standard deviation.

Even though $\mathrm{C} 2$ showed consistently lower air permeability than $\mathrm{C}$, differences could not be very significant when considering the variability of the results.

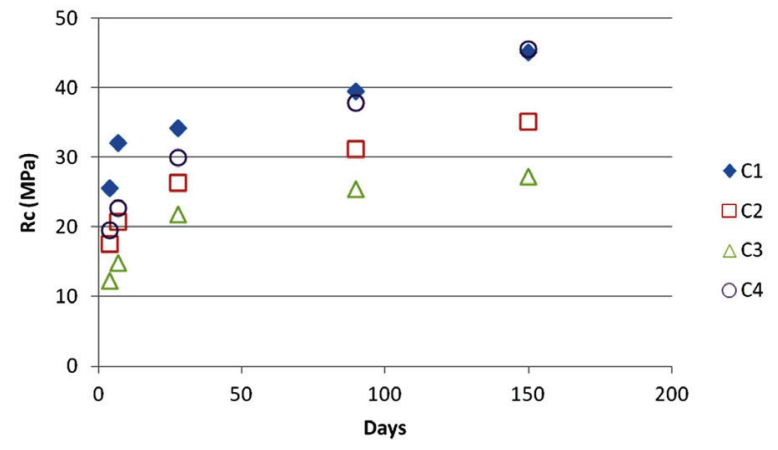

Fig. 4. Strength gain of $\mathrm{C} 1, \mathrm{C} 2, \mathrm{C} 3$ and $\mathrm{C} 4$ concrete mixtures

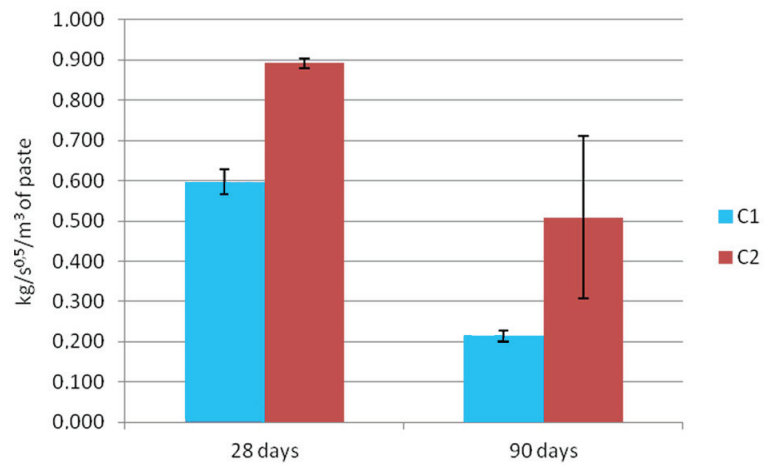

Fig. 5. Sorptivity change in time of $\mathrm{C} 1$ and $\mathrm{C} 2$ concrete mixtures normalized by paste content by volume

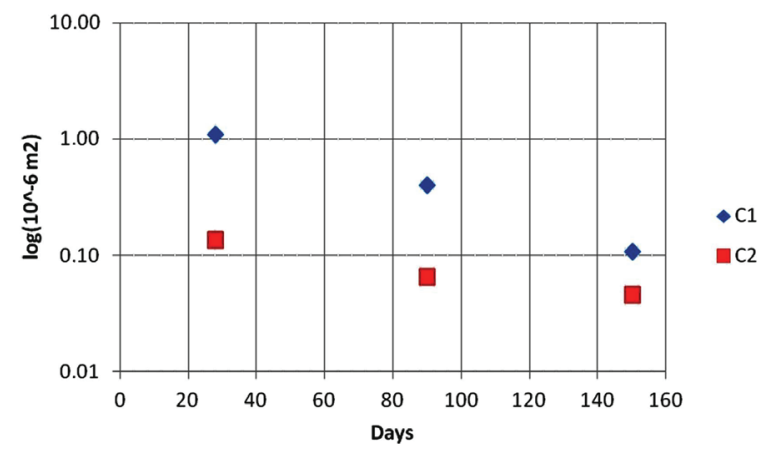

Fig. 6. Air permeability change in time of $\mathrm{C} 1$ and $\mathrm{C} 2$ concrete mixtures 
Table 6. Standard deviation of air permeability

\begin{tabular}{lccc}
\hline Age (days) & 28 & 90 & 150 \\
\hline $\mathrm{dv}$ C1 & 0.39 & 0.62 & 0.13 \\
\hline $\mathrm{dv}$ C2 & 0.10 & 0.06 & 0.06 \\
\hline
\end{tabular}

Both concrete mixtures, $\mathrm{C} 1$ and $\mathrm{C} 2$, showed constant decrease in air permeability with age. Since air permeability is shown in logarithmic scale, the decrease in permeability between 28 and 150 days was 88 and $84 \%$ for $\mathrm{C} 1$ and $\mathrm{C} 2$, respectively.

Initially (i.e. 28 days of age), $\mathrm{C} 2$ with natural pozzolans showed an air permeability of about one tenth than that of $\mathrm{C} 1$ with OPC. However, $\mathrm{C} 1$ showed an important decrease between 28 and 150 days reaching an air permeability of approximately 2 times of that of $\mathrm{C} 2$. It is important to consider that $\mathrm{C} 2$ showed significantly lower variability than $\mathrm{C} 1$ which suggest a more uniform pore structure.

\subsubsection{Chloride ion diffusion}

Since the use of SCMs, such as natural pozzolans, can have a very significant effect on the chemistry of the pore solution affecting the electrical conductivity of concrete (Shi 2004), the comparison between chloride ion diffusion of $\mathrm{C} 1$ and $\mathrm{C} 2$, might not represent solely a change in microstructure but also an effect of the testing method.

The test of the samples presented problems that could not give representative results, so they were omitted. Nevertheless, a previous study (Lopez, Castro 2010) made with the same constituents, and test equipment showed beneficial effects with the inclusion of natural pozzolans in chloride ion diffusion. In that study, which tested mixtures similar to $\mathrm{C} 1$ and $\mathrm{C} 2$, the use of NP decreased chloride ion diffusion at 90 days by $50 \%$.

\subsection{Effect of ITZ}

The effect of ITZ on compressive strength and transport properties is analysed by comparing the performance of $\mathrm{C} 2, \mathrm{C} 3$, and $\mathrm{C} 4$ concretes all with the same constituents and $w / b$, but different aggregate-to-paste ratio; i.e. different ITZ content.

ITZ was assumed to be proportional to the surface density of the aggregate of concrete. A first approach to estimate the aggregate surface was made assuming aggregates particles as spheres. Each aggregate particle was represented by a sphere inscribed at its minimum dimension. The amount of particles of each size was calculated based on the sieve analysis and the actual mixture design.

In order to determine the goodness of this approach, an unbiased stereology technique was applied to micrographs obtained using optical microscopy. Two different magnifications were used, $18 \mathrm{x}$ and $54 \mathrm{x}$, in order to establish the best for measuring the surface density of the aggregate $(S v)$ according to Eqn (1). Four micrographs were used from each concrete mixture to assess $S v a t$ each magnification.
Figure 7 shows micrographs from $\mathrm{C} 2, \mathrm{C} 3$ and $\mathrm{C} 4$ with $18 x$ of magnification.

$S v$ calculated using Eqn (1) and the respective result with the "spherical approximation" are shown in Table 7. The order used to display the results starts with the mixture with more aggregate content (C3) and finished with that with less aggregate content $(\mathrm{C} 4)$.

Since the visible aggregate particle size varies with magnification, the values obtained using stereology might also vary with magnification. It was established that the visible range at $18 \mathrm{x}$ magnification started at $0.11 \mathrm{~mm}$ while that for $54 \mathrm{x}$ magnification started at $0.028 \mathrm{~mm}$.

The large difference between $S v$ estimated using stereology and the spherical approximation indicates that the latter is not conservative since underestimated $S v$ and so does the amount of ITZ. This underestimate is mainly due to the fact that the crushed aggregate used in this investigation do not have a round and regular shape, so their actual surface is much higher than that estimated by the spheres. Furthermore, the spheres are inscribed in the minimum size of the aggregate.

A comparison between spheres approximation and stereology with micrographs was also made, inscribing circumferences in the minimum size of aggregate particles and then applying stereology with cycloids, as show Figure 8 .

The analysis showed that considering aggregate being spheres under estimate aggregate surface density by at least $44 \%$.

When comparing the stereology results from each magnification, it can be concluded that only the results from 54x followed the expected trend of increasing $S v$ with the increase of aggregate content. Thus, $S v$ obtained at $54 \mathrm{x}$ was used to represent the amount of ITZ and to evaluate the ITZ effect on transport properties.

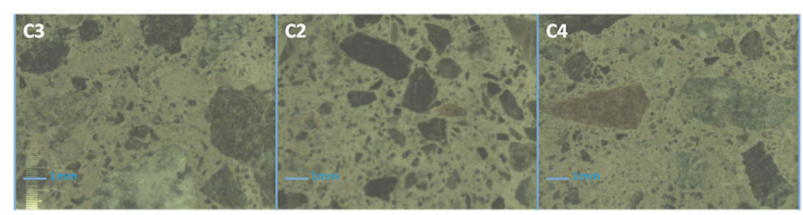

Fig. 7. Micrographs from $\mathrm{C} 2, \mathrm{C} 3$, and $\mathrm{C} 4$ concrete mixtures

Table 7. Aggregate surface density $(S v)$

\begin{tabular}{lccccc}
\hline & Technique & Magnification & $\mathrm{C} 3$ & $\mathrm{C} 2$ & $\mathrm{C} 4$ \\
\hline $\begin{array}{l}\mathrm{Sv} \\
\left(\mathrm{m}^{-1}\right)\end{array}$ & Microscopy & 54 & 11770 & 10339 & 9426 \\
\hline $\mathrm{dv}$ & & 18 & 3328 & 4623 & 3895 \\
\hline $\begin{array}{l}\mathrm{Sv} \\
\left(\mathrm{m}^{-1}\right)\end{array}$ & Microscopy & 1.2 & 1.5 & 1.3 \\
\hline $\mathrm{dv}$ & & 0.2 & 0.6 & 0.7 \\
\hline $\begin{array}{l}\mathrm{Sv} \\
\left(\mathrm{m}^{-1}\right)\end{array}$ & Spheres & 54 & 716 & 676 & 637 \\
\hline $\begin{array}{l}\mathrm{Sv} \\
\left(\mathrm{m}^{-1}\right)\end{array}$ & Spheres & 18 & 745 & 703 & 663 \\
\hline
\end{tabular}




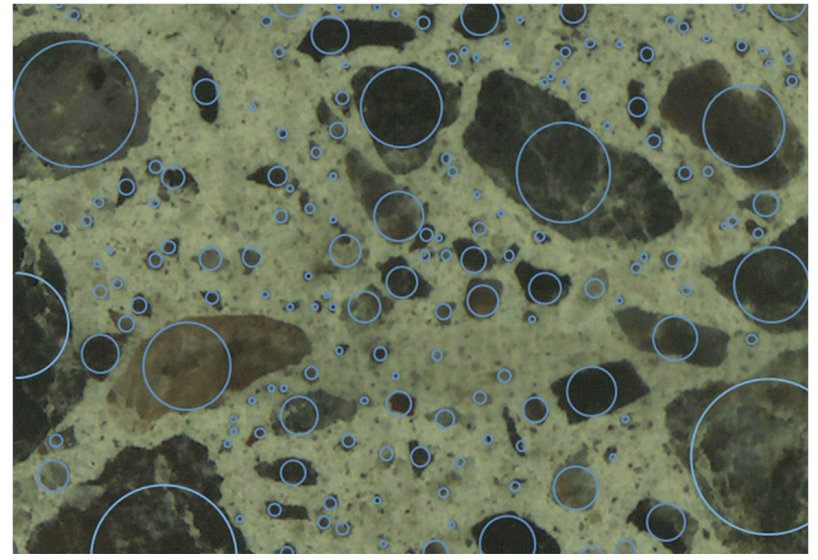

Fig. 8. Comparison between spherical approximation and stereology

\subsubsection{Compressive strength}

Figure 9 presents the compressive strength obtained in mixtures $\mathrm{C} 2, \mathrm{C} 3$, and $\mathrm{C} 4$ versus $\mathrm{Sv}$ as calculated using the stereology technique with magnification of 54x. Table 8 presents the standard deviation obtained in the test.

The effect of the $S v$ (and amount of ITZ) on compressive strength is very pronounced as shown in Figure 9. Compressive strength decreases as $S v$ increase; and this reduction seems to approximate to a linear relationship for all ages and more pronounced as compressive strength increases. That is, as age and compressive strength increases, the drop in strength with $S v$ shows a steeper slope.

\subsubsection{Sorptivity coefficient}

It is clear that high $S v$ (and amount of ITZ) leads higher capillary suction of water while low $S v$ has low capillary suction (Fig. 11). Also, reduction of sorptivity

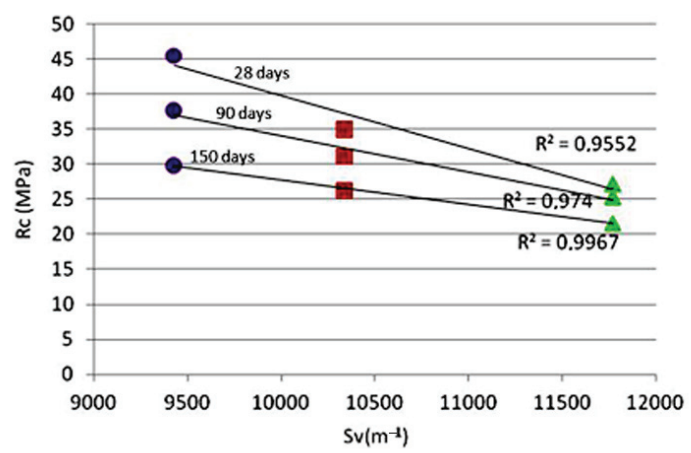

$\square c 2$

$\triangle \mathrm{C3}$

- $C 4$

Fig. 9. Compressive strength versus surface density of the aggregate $(S v)$

Table 8. Standard deviation of compressive strength

\begin{tabular}{lccc}
\hline Age (days) & 28 & 90 & 150 \\
\hline C3 & 0.97 & 0.89 & 0.61 \\
\hline C2 & 0.09 & 0.78 & 2.56 \\
\hline C4 & 0.87 & 0.52 & 0.00 \\
\hline
\end{tabular}

coefficient with age is not constant for all mixtures, high $S v$ has a greater reduction in sorptivity coefficient that low $S v$ between 28 and 90 days. Since all concrete mixtures have the same $\mathrm{w} / \mathrm{b}$ (i.e. with similar pore structure and permeability of the bulk paste) and measurements were normalized by paste content and aggregate absorption, it is concluded that ITZ has a main role in determining sorptivity coefficient of concrete. Table 9 presents the standard deviation obtained in the test.

\subsubsection{Air permeability}

$S v$ (and amount of ITZ) has a pronounced effect on the air permeability; it is clear that high $S v$ leads to higher air permeability while low $S v$ has low air permeability (Fig. 11). However, such effect does not seem to be linear since an increase in $10 \%$ in $S v$ between $\mathrm{C} 4$ and $\mathrm{C} 2$ led to an increase in air permeability of $35 \%$, and an increase in $12 \%$ in $S v$ between C2 and C3 led to an increase in air permeability of $91 \%$. Table 10 presents the standard deviation obtained in the test.

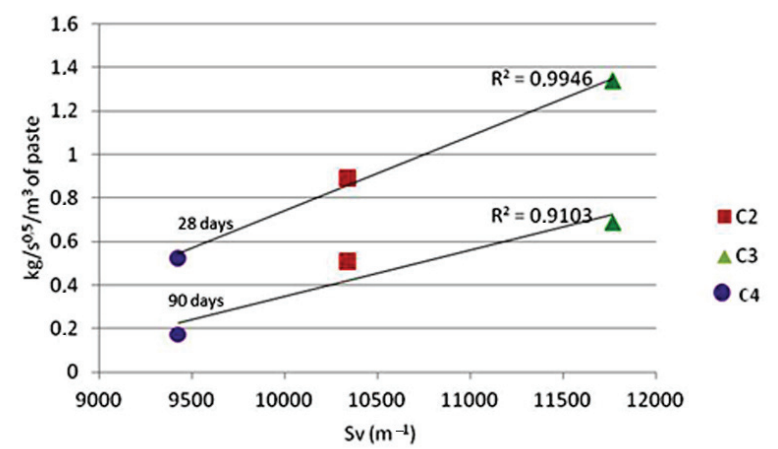

Fig. 10. Sorptivity coefficient vs. surface density of aggregate (Sv)

Table 9. Standard deviation of sorptivity coefficient

\begin{tabular}{lcc}
\hline Age (days) & 28 & 90 \\
\hline C3 & 0.398 & 0.092 \\
\hline C2 & 0.012 & 0.203 \\
\hline C4 & 0.006 & 0.176 \\
\hline
\end{tabular}

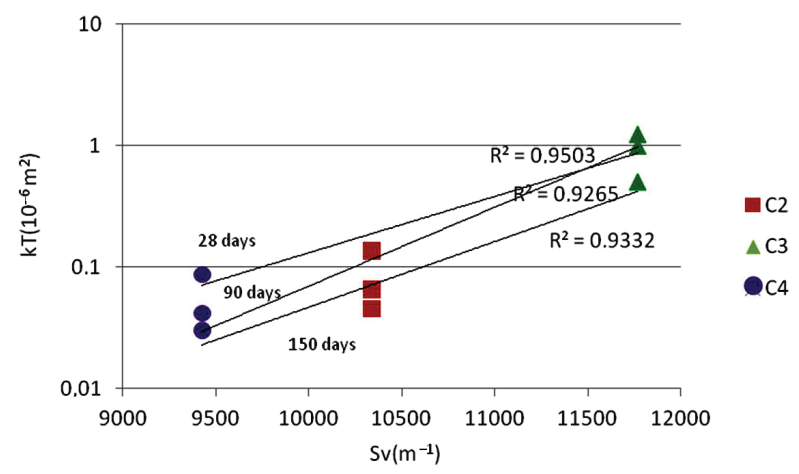

Fig. 11. Air permeability (logarithmic scale) vs. surface density of the aggregate $(S v)$ 


\subsection{Comparative analysis}

\subsubsection{Chloride ion diffusion}

The effect of Sv (and amount of ITZ) is important in chloride ion diffusion; as $\mathrm{Sv}$ increases, chloride ion diffusion increases too (Fig. 12). This effect seems to be similar at different ages. Since the results of chloride ion diffusion of $\mathrm{C} 2$ were not included, it is not possible to determine whether the effect of $\mathrm{Sv}$ on chloride ion diffusion is linear or no not. Table 11 presents the standard deviation obtained in the test.

It is also of interest to determine which factor (natural pozzolans or amount of ITZ) has the greater effect on transport properties. $\mathrm{C} 1$, concrete mixture with OPC was chosen as the control mixture for analysing the effect of the natural pozzolans, and $\mathrm{C} 3$, concrete mixture with the highest amount of ITZ, was chosen as the control mixture for analysing the effect of ITZ. Figure 13 shows the relative effect of each factor on compressive strength.

For compressive strength, the efficiency of concrete with blended cement $(68 \%$ OPC $+38 \%$ of natural pozzolans) ranged between 65 and $79 \%$ of that obtained for concrete with OPC only (C2 versus $\mathrm{C} 1)$. It should be pointed out that there is an improvement in the efficiency of mixtures with blended cement after the first week, but it seems to stabilize after 28 days. On the other hand, the efficiency of concrete with more ITZ $\left(S v=11770 \mathrm{~m}^{-1}\right)$ was approximately $65 \%$ of that obtained for concrete with less ITZ $\left(S v=9426 \mathrm{~m}^{-1}\right)(\mathrm{C} 3$ versus $\mathrm{C} 4)$, and no

Table 10. Standard deviation of air permeability

\begin{tabular}{lccc}
\hline Age (days) & 28 & 90 & 150 \\
\hline C3 & 1.45 & 1.28 & 0.87 \\
\hline C2 & 0.10 & 0.06 & 0.06 \\
\hline C4 & 0.6 & 0.4 & 0.3 \\
\hline
\end{tabular}

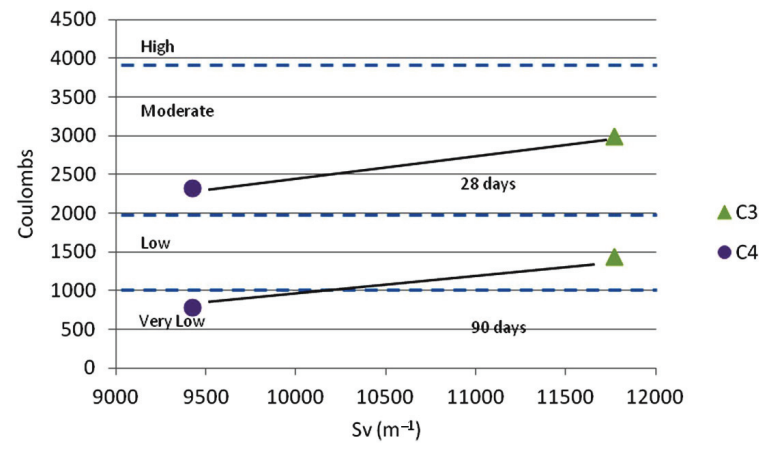

Fig. 12. Chloride ion diffusion vs. surface density of the aggregate $(S v)$

Table 11. Standard deviation of chloride ion diffusion

\begin{tabular}{lcl}
\hline Age (days) & 28 & 90 \\
\hline C3 & 256.7 & 5.1 \\
\hline C4 & 391.1 & 0.8 \\
\hline
\end{tabular}

clear improvement was observed at later ages. The effects of using blended cement with $38 \%$ of natural pozzolans or increasing the amount of ITZ by $44 \%$ seem to be on the same order of magnitude.

Figure 14 shows the relative effect of the use of natural pozzolans and amount of ITZ on sorptivity coefficient.

When the amount of paste is considered in the measurements, concrete with blended cement (68\% OPC $+38 \%$ natural pozzolans) had a greater sorptivity coefficient than that of concrete with OPC only ( $\mathrm{C} 1$ versus $\mathrm{C} 2$ ). The increase in sorptivity coefficient ranged between 50 and $140 \%$ at 28 and 90 days of age, respectively when natural pozzolans were considered. On the other hand, the decrease in ITZ decreased sorptivity coefficient by 60 and $75 \%$ at 28 and 90 days of age, respectively (C3 versus $\mathrm{C} 4$ ). Since sorptivity coefficient of $\mathrm{Cl}$ (without natural pozzolans) was similar to that of $\mathrm{C} 4$ (with natural pozzolans and lower ITZ), it can be concluded that using blended cement with $38 \%$ of natural pozzolans or decreasing the amount of ITZ by $20 \%$ have a similar effect in magnitude on sorptivity coefficient of concrete.

Figure 15 shows the relative effect of the use of natural pozzolans and amount of ITZ on air permeability.

Air permeability showed a greater sensitivity to the factor under study than compressive strength and sorptivity coefficient. Contrary to what was observed

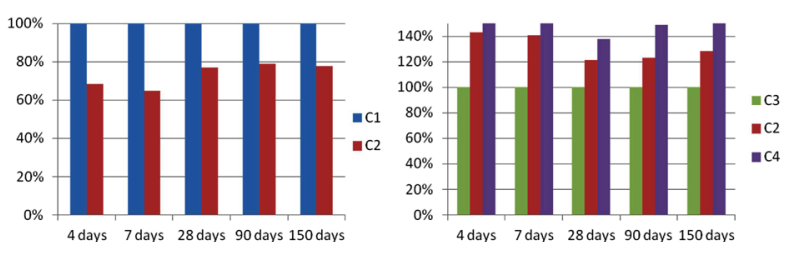

Fig. 13. Effect of the use of natural pozzolans and change in amount of ITZ in compressive strength
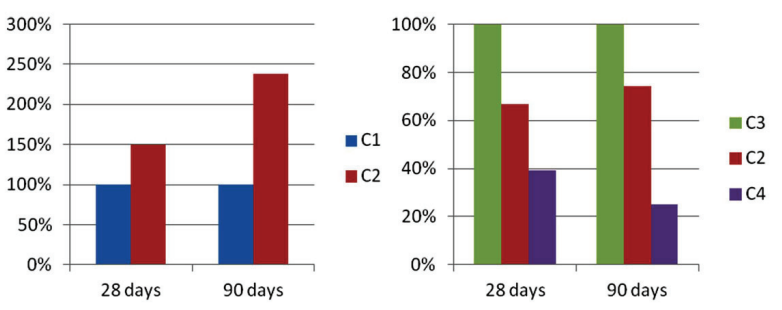

Fig. 14. Effect of the use of natural pozzolans and change in amount of ITZ in sorptivity coefficient
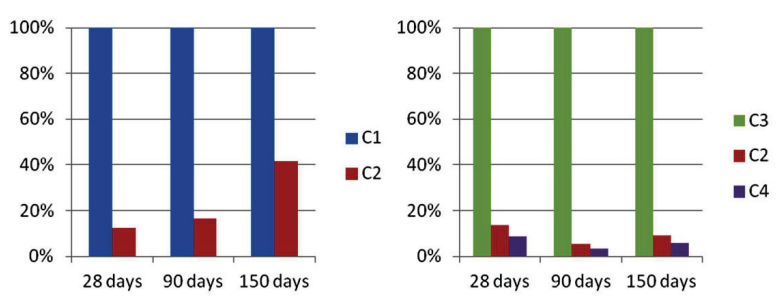

Fig. 15. Effect of the use of natural pozzolans and change in amount of ITZ in air permeability 


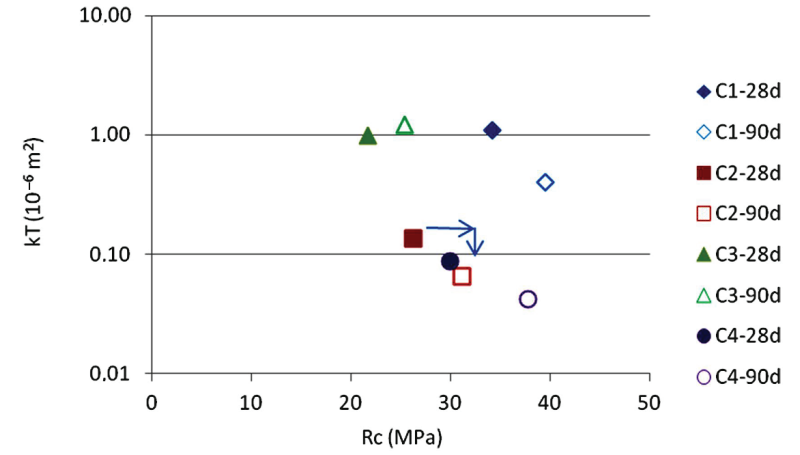

Fig. 16. Compressive strength vs. air permeability (logarithmic scale)

for sorptivity coefficient, concrete with blended cement (68\% OPC $+38 \%$ natural pozzolans) had much lower air permeability than that of concrete with OPC only $(\mathrm{C} 1$ versus $\mathrm{C} 2$ ). The use of blended cement decreased air permeability by $27 \%$. On the other hand, the increase in ITZ greatly increased air permeability by $94 \%$ (C3 versus $\mathrm{C} 4)$. In this case, using blended cement with $38 \%$ of natural pozzolans or increasing the amount of ITZ by $44 \%$ had opposite effects on concrete performance.

Overall, it can be stated that the use of blended cement with natural pozzolans has an opposite effect in compressive strength than in air permeability.

Additionally, the effect of the amount of ITZ is of much more impact on air permeability than in compressive strength. Figure 16 compares the variation in compressive strength and air permeability for all four mixtures under investigation.

Compressive strength and air permeability are greatly affected by the type of cement and amount of ITZ as shown by the wide range in both variables in Figure 16. Compressive strength varied from 20 to $40 \mathrm{MPa}$ and air permeability from 0.05 to $1.1 \times 10^{-6} \mathrm{~m}^{2}$ for mixtures under investigation in despite of all having a w/b at 0.5 . It is concluded that the type of cement and amount of ITZ are as important as $\mathrm{w} / \mathrm{b}$ in determining compressive strength and air permeability.

Compressive strength and air permeability are not directly dependent on one another. For instance, $\mathrm{C} 1$ at 90 days had a compressive strength of $40 \mathrm{MPa}$ and air permeability of $0.8 \times 10^{-6} \mathrm{~m}^{2}$, and $\mathrm{C} 2$ at 28 days a compressive strength of $25 \mathrm{MPa}$ and air permeability of $0.2 \times 10^{-6} \mathrm{~m}^{2}$; the effect in air permeability is greater than the effect in compressive strength. Thus, specifying a high strength concrete does not mean that air permeability, and ultimately, durability are adequate.

\section{Concluding remarks}

Environmental and economic issues have increased the interest of creating more durable buildings and infrastructure. Concrete may greatly contribute to this goal by reducing its permeability.

This research aimed to determine the effect of using blended cement (OPC + natural pozzolans) and varying the amount of ITZ in reducing the permeability of concrete.

The use of blended cement with natural pozzolans decreased air permeability and chloride ion diffusion by 84 and $50 \%$ respectively, but increased sorptivity coefficient between 28 and 90 days of age by 50 and $140 \%$. This unexpected increase in sorptivity coefficient does not necessarily mean higher permeability or a more interconnected pore structure in concrete containing NP. The increase in sorptivity coefficient might be a consequence of refinement of the pore structure and lower saturation of the pore network of concrete with NP. This needs to be further investigated.

An increase in the amount of ITZ, represented by surface density of the aggregate, decreased compressive strength and increased transport properties. Nevertheless, it is worth to notice that the effect of the amount of ITZ in air permeability is significantly higher than that on sorptivity coefficient and chloride ion diffusion. It is also of relevance to mentioned again that even reducing ITZ, by reducing surface density (aggregate content), exits a limit of cement content where heat/shrinkage related cracking may increase transport properties to and it needs to be further investigated.

Transport properties, and particularly air permeability, seem to be very sensitive to changes in the amount of ITZ even at constant w/b and cement type. It is concluded that considering ITZ, represented by surface density of the aggregate, becomes important in controlling permeability of concrete.

The surface density from the stereological approach is an accurate alternative for assessing ITZ in concrete since the amount of ITZ does not linearly depend on aggregate content and it is not well represented by assuming aggregate particles as spheres. Furthermore, an appropriate magnification for the micrographs must be chosen.

Even though compressive strength and permeability are affected by the use of natural pozzolans and changes in the amount of ITZ, those effects vary importantly. This means that an increase in strength does not necessarily imply a decrease in permeability, so minimizing permeability for a durable concrete is not equivalent to maximizing its compressive strength.

An adequate mixture design is very important in achieving a durable concrete. Mixtures with lower aggregate content will have lower permeability and better durability. Also, the use of SCMs, such as natural pozzolans, might not be enough to reduce permeability of concrete if concrete includes a large amount of aggregate (i.e. ITZ).

\section{Acknowledgements}

Authors greatly acknowledge the support given by the FONDEF (Fund for scientific and technological development) through Project D07I1076.Additionally, authors also thank the support from Dictuc S.A., Instituto del Cemento y del Hormigón de Chile (ICH), Universidad de Valparaíso, and the insightful comment from Roberto Torrent, Luis Ebensperger, and the reviewers. 


\section{References}

Alexander, M. G. 2005. Aggregates in concrete. New York: Taylor and Francis. 435 p.

ASTM C39/C39M-09a. Standard test method for compressive strength of cylindrical concrete specimens. West Conshohocken: ASTM, 2009.

ASTM C496/C496M-04. Standard test method for splitting tensile strength of cylindrical concrete specimens. West Conshohocken: ASTM, 2004.

ASTM C469-02. Standard test method for static modulus of elasticity and Poisson's ratio of concrete in compression. West Conshohocken: ASTM, 2002.

ASTM C1585-04. Standard test method for measurement of rate of absorption of water by hydraulic-cement concretes. West Conshohocken: ASTM, 2004.

ASTM C1202-10. Standard test method for electrical indication of concrete's ability to resist chloride ion penetration. West Conshohocken: ASTM, 2010.

ASTM C618-08a. Standard test method for coal fly ash and raw or calcined natural pozzolan for use in concrete. West Conshohocken: ASTM, 2008.

Bentz, D. P. 2002. Sorptivity-based service life predictions for concrete pavements. Gaithersburg, MD: NIST.

Bourdette, B.; Ringot, E.; Ollivier, J. P. 1995. Modelling of the Transition Zone Porosity, Cement and Concrete Research 25(4): 741-751. http://dx.doi.org/10.1016/0008-8846(95)00064-J

Carcasses, M.; Ollivier, J.-P. 1999. Transport by permeation, in Alexander, M. G.; Arliguie, G.; Ballivy, G.; Bentur, A.; Marchand, J. (Eds.). Engineering and Transport Properties of the Interfacial Transition Zone in Cementitious Composites. RILEM Publications S.A.R.L., 149-156.

Castro, J.; Bentz, D.; Weiss, J. 2011. Effect of sample conditioning on the water absorption of concrete, Cement and Concrete Composites 33(8): 805-813. http://dx.doi.org/10.1016/j.cemconcomp.2011.05.007

CEB, C. E.-I. 1997. Durable concrete structures. London: Thomas Terford.

Colak, A. 2002. Characteristics of pastes from a Portland cement containing different amount of natural pozzolans, Cement and Concrete Research 33(4): 585-593. http://dx.doi.org/10.1016/S0008-8846(02)01027-X

Espinoza, G.; Paul, Á.; Lopez, M. 2010. Concrete containing natural pozzolans: new challenges for internal curing, Journal of Materials in Civil Engineering 24(8): 981-988. http://dx.doi.org/10.1061/(ASCE)MT.1943-5533.0000421

Ferreira, R. M. 2010. Implication on RC structure performance of model parameter sensitivity: effect of chlorides, Journal of Civil Engineering and Management 16(4): 561-566. http://dx.doi.org/10.3846/jcem.2010.62

Garboczi, E. 1995. Microstructure and transport properties of concrete, in Kropp, J. A. (Ed.). Performance criteria for Concrete Durability. London: E and FN Spon, 126-134.

Hazaree, C.; Wang, K.; Ceylan, H.; Gopalakrishnan, K. 2010. Capillary transport in RCC: water/cement-strenght-FT-resistance, Journal of Materials in Civil Engineering 23(8): 1181-1191.

Hooton, D. M.-C. 2006. Proportioning and testing concrete for durability, Concrete International 38-41.

Howard, C. V.; Reed, M. G. 2005. Unbiased stereology. New York: Garland Science/BIOS Scientific Publishers. 277 p.

Kliukas, R.; Kudzys, A. 2004. Probabilistic durability prediction of existing building elements, Journal of Civil Engineering and Management 10(2): 107-112. http://dx.doi.org/10.1080/13923730.2004.9636294
Lopez, M.; Castro, J. T. 2010. Effect of natural pozzolans, RIC 25(3): 419-431.

Mehta, P. K. 1991. Durability of concrete - fifty years of progress? ACI Material Journal, Special Publication 126: 1-31.

Mehta, P. K.; Monteiro, P. J. 2006. Concrete: microstructure, properties and materials. New York: McGraw-Hill. $659 \mathrm{p}$.

Mills, R. 1987. Mass transfer of gas and water trough concrete, ACI Special Publication 100: 621-644.

Mindness, S. 2005. Compressive strength. The wrong way to assess concrete, in Skalny, J. M. (Ed.). Concrete technology. John Wiley and Sons, 3-19.

Neville, A. 2001. Consideration of durability of concrete structures: past, present, and future, Materials and Structures 5.

Neville, A. 2004. Properties of concrete. New York: John Wiley and Sons, Inc. $864 \mathrm{p}$.

Papadakis, V. G.; Tsimas, S. 2002. Suplementary cementing materials in concrete. Part I: efficiency and design, Cement and Concrete Research 32(10): 1525-1532. http://dx.doi.org/10.1016/S0008-8846(02)00829-3

Pereira de Oliveira, L. A.; de Castro Gomes, J. P.; Pereira, C. N. G. 2006. Study of sorptivity of self-compacting concrete with mineral aditives, Journal of Civil Engineering and Management 12(3): 215-220. http://dx.doi.org/10.1080/13923730.2006.9636395

Ping, X.; Beaudoin, J. J.; Brousseau, R. 1991a. Flat aggregateportland cement paste interfaces, I. Electrical conductivity models, Cement and Concrete Research 21(4): 515-522. http://dx.doi.org/10.1016/0008-8846(91)90101-M

Ping, X.; Beaudoin, J.; Brousseau, R. 1991b. Effect of aggregate size on transition zone properties at the portland cement paste interface, Cement and Concrete Research 21(5): 999-1005. http://dx.doi.org/10.1016/0008-8846(91)90166-F

Powers, T. 1960. Physical properties of cement paste. Portland Cement Association, Bulletin. 154 p.

Powers, T.; Copeland, L.; Mann, H. 1959. Capillary continuity or discontinuity in cement pastes. Portland cement Association, Bulletin. 110 p.

Richardson, M. G. 2004. Fundamentals of durable reinforced concrete. London: Taylor and Francis e-Library. 272 p.

Rodríguez-Camacho, R.; Uribe-Afif, R. 2002. Importance of using the natural pozzolans oc concrete durability, Cement and Concrete Research 32(12): 1851-1858. http://dx.doi.org/10.1016/S0008-8846(01)00714-1

Sabir, B. B.; Wild, S.; Bai, J. 2001. Metakaolin and calcined clays as pozzolans for concrete: a review, Cement and Concrete Composites 23(6): 441-454. http://dx.doi.org/10.1016/S0958-9465(00)00092-5

Shen, L.-Y.; Hao, J. L.; Tam, V. W.-Y.; Yao, H. 2007. A checklist for assessing sustainability performance of construction projects, Journal of Civil Engineering and Management 13(4): 273-281. http://dx.doi.org/10.1080/13923730.2007.9636447

Shi, C. 2004. Effect of mixing proportions of concrete on its electrical conductivity and the rapid chloride permeability test (ASTM C1202 or ASSHTO T277) results, Cement and Concrete Research 34(3): 537-545. http://dx.doi.org/10.1016/j.cemconres.2003.09.007

Swiss-Standard. 2003. SIA 262/1-E Standars Method. Nondestructuve site air permeability test.

Torrent, R.; Ebensperger, L. 2010. Concrete air permeability "in situ" test: status quo, Revista Ingeniería de Construcción 371-382. 
Tumidajski, P. 1996. Electrical conductivity of Portland cement mortars, Cement and Concrete Research 26(4): 529-534. http://dx.doi.org/10.1016/0008-8846(96)00027-0

Uzal, B.; Turanli, L. 2003. Studies of blended cements containing a high volume of natural pozzolans, Cement and Concrete Research 33(11): 1777-1781. http://dx.doi.org/10.1016/S0008-8846(03)00173-X
Zhang, M.-H.; Gjorv, O. E. 1991. Permeability of high-strength lightweight concrete, ACI Materials Journal 88(5): 463-469.

Zhang, X.; Han, J. 2005. Analytic methods and theory of quantitative stereology for the determination of concrete proportioning in structural components, Cement and Concrete Research 35(9): 1855-1858.

Fernando BUSTOS. He received his BSs and MSc from Pontificia Universidad Catolica de Chile in 2009 and 2011, respectively. His research interests are in sustainable construction and materials science. He is currently working in the field for a construction company.

Patricia MARTINEZ. She received her PhD from Pontificia Universidad Catolica de Chile in 2003. She is member of Chilean Network of Life Cycle Analysis. She is researcher at the Pontificia Universidad Catolica de Chile on materials for heritage, and an Associate Professor at the Universidad de Valparaiso. Her research interests sustainable construction with special focus on concrete, durability of structures, and heritage.

Carlos VIDELA. He received his PhD from The University of Birmingham in 1989. He actively participates in the American Concrete Institute and is a past chairman of the ACI209 committee on creep and shrinkage in concrete. He is a Professor at the School of Engineering of the Pontificia Universidad Catolica de Chile. His research interests are early age properties, creep and shrinkage, and durability of concrete structures.

Mauricio LOPEZ. He received his PhD from Georgia Institute of Technology in 2005. He participates in the American Concrete Institute in several technical committees and currently leads two subcommittees. He is an Associate Professor at the School of Engineering of the Pontificia Universidad Catolica de Chile. His research interests are durability of structures, materials science of concrete, microstructure-property relationships, and high performance concrete. 